\title{
Comparison of Different Scoring Systems in Predicting the Severity of Acute Pancreatitis: A Prospective Observational Study
}

N. R. Venkatesh ${ }^{1}$, Chellappa Vijayakumar ${ }^{1}$, Gopal Balasubramaniyan ${ }^{1}$, Sakthivel Chinnakkulam Kandhasamy 1, 2, 3, 4 , Sudharsanan Sundaramurthi ${ }^{1}$, Sreenath G. S. ${ }^{1}$, Krishnamachari Srinivasan ${ }^{1}$

1. Surgery, Jawaharlal Institute of Postgraduate Medical Education and Research, Puducherry, IND 2. General Surgey, Madras Medical College, Chennai, IND 3. General Surgery, Vardhman Mahavir Medical College and Safdarjung Hospital, New Delhi, IND 4. Post Graduate Diploma In Medico-Legal Aspetcs, Tamil Nadu Dr. Ambedkar Law University, Chennai, IND

Corresponding author: Gopal Balasubramaniyan, drbala18@gmail.com

\section{Abstract}

\section{Background}

Acute pancreatitis (AP) is an inflammatory condition of the pancreas mostly due to alcohol or gallstones. Various scoring systems were involved in identifying the severity of the disease. The standard single score to identifying the severity remains uncertain.

\section{Methodology}

This prospective observational study was carried out for two years in a tertiary care center from South India. The diagnosis of AP was made based on Atlanta criteria, and a total of 164 patients were included. All patients were assessed by acute physiology and chronic health evaluation 11 (APACHE II), bedside index for severity in AP (BISAP), modified Glasgow score (MGS), and Ranson score on admission and 48 hours after admission scores. Procalcitonin was done in all patients with AP. Contrast-enhanced computed tomography (CT) of the abdomen was done in 69 patients who had features of severe acute pancreatitis (SAP). Sensitivity, specificity, positive predictive value (PPV), negative predictive value (NPV), and diagnostic accuracy were calculated for each score, and procalcitonin for CT documented severe patients and organ failure patients together.

\section{Results}

A total of 164 patients were included in this study. CT abdomen showed a modified CT severity index (MCSI) $\geqslant 8$ in all 69 (100\%) patients. APACHE II score could predict SAP based on CT findings in 44 patients (63.76\%), BISAP score in 22 patients (31.88\%), MGS in 55 patients (79.71\%), Ranson score at admission in 31 patients (44.92\%), Ranson score 48 hours after admission in 44 patients (63.76\%), and procalcitonin on admission in 69 patients (100\%) when cut-off used as per the literature. APACHE II score could predict SAP in cases of AP ( $\mathrm{n}=164)$ in 52 patients (50\%), BISAP score in 27 patients (26\%), MGS in 79 patients (76\%),

Received 02/04/2020 Review began 02/07/2020 Review ended 02/07/2020 Published 02/10/2020

\section{() Copyright 2020}

Venkatesh et al. This is an open access article distributed under the terms of the Creative Commons Attribution License CC-BY 4.0., which permits unrestricted use, distribution, and reproduction in any medium, provided the original author and source are credited.
Ranson score at admission in 34 patients (33\%), and Ranson score 48 hours after admission in 61 (59\%) patients when cut-off was used as per the literature. This study demonstrated that Ranson score on admission had a good area under the curve (AUC). AUC (0.8483), APACHE II (AUC 0.7708), and Ranson score 48 hours after admission (AUC 0.8167) had a fair accuracy. BISAP (AUC 0.6399) and MGS (AUC 0.6486) had poor accuracy for the prediction of severity in AP based on receiver operator characteristic (ROC) curves.

\section{Conclusion}

Among the scoring system compared, MGS had the highest sensitivity for predicting the severity of AP. However, Ranson score on admission had better diagnostic accuracy for predicting severity, organ failure, and mortality based on ROC curves. Procalcitonin had the best sensitivity, specificity, PPV, NPV, and diagnostic accuracy for association with severity in AP.

Categories: Emergency Medicine, Gastroenterology, General Surgery

Keywords: modified glasgow score, acute pancreatitis, apache ii score, bisap score, ranson score, procalcitonin

\section{Introduction}

Acute pancreatitis (AP) is a sudden inflammation of the pancreas, which is characterized by the activation of pancreatic enzymes to cause self-digestion of the pancreas. It is an acute inflammatory process presenting as a mild discomfort with local inflammation to severe disease with multi-organ failure. It has a mortality of approximately $1 \%$ among all AP but so high as $20 \%$ to $30 \%$ among those with severe acute pancreatitis (SAP), which is a process of acute inflammation of the pancreas with the involvement of regional tissues or organ systems [1]. AP is a common clinical condition, yet no prevalence data are not available from India. 
Only incidence is available from tertiary centers 55 patients per year [1]. The incidence of AP has been reported to be higher in the USA, Finland, and Scotland (49.3, 46.6, and 41.9 per 100,000 population, respectively) [2].

Gallstones and alcohol are the most common causes of AP in India [3]. Other causes are hypercalcemia, drug-induced pancreatitis, and dyslipidemia. Smoking also has been found to be a cause in $30 \%$ of the patients which also carries higher mortality (20\%) [4]. A study from Sweden invited for a health questionnaire, which found smoking was associated with AP with a relative risk of 3.57 among those who had no history of alcohol consumption [5]. There are several indices in use to evaluate pancreatitis patients. Therefore, an attempt has been made to identify which scoring system predicts the severity in AP in this study. Secondarily, it aimed to assess the correlation between procalcitonin level and severity of AP.

\section{Materials And Methods}

This prospective observational study was carried out for two years in a tertiary care center from South India. Patients who presented with acute abdomen were examined, and in suspected cases of pancreatitis, serum amylase along with ultrasonography of the abdomen was done. The diagnosis of AP was made based on the Atlanta criteria, and a total of 164 patients were included. Informed consent was obtained from all participants, and this study was approved by the Institute Ethics Committee. All patients with chronic pancreatitis and those who were treated outside before presenting to the emergency were excluded from the study.

Various clinical and biochemical parameters were studied on admission and 48 hours after admission. Data were collected regarding demographics, detailed history, and physical examination, including complete hemogram, liver function test, and procalcitonin levels. Procalcitonin value of $0.5 \mathrm{ng} / \mathrm{mL}$ was accounted as the cut-off value for identifying the severity of AP as per the literature.

Patients were managed as per the standard institute guidelines. Patients who improved within 72 hours were labeled mild AP. If symptoms persisted after 72 hours, or no clinical improvement was there, contrastenhanced computed tomography (CT) of the abdomen was done for those without organ failure. CT findings were graded as per the modified CT severity index (MCSI). CT findings and/or evidence of organ failure were taken as the gold standard for diagnosing severity using the Atlanta criteria, and it was used to compare four scores. All patients were assessed for acute physiology and chronic health evaluation (APACHE) II score, bedside index for severity in AP (BISAP), modified Glasgow score (MGS), and Ranson score on the first 24 hours and 48 hours after to it. Patients were followed up until discharge or death.

\section{Statistical analysis}

OpenEpi statistical software was used to analyze the data, and the receiver operator characteristic (ROC) curve was plotted with all the scores and procalcitonin using the data generated. Sensitivity, specificity, positive predictive value (PPV), negative predictive value (NPV), and diagnostic accuracy of all four scores for predicting CT diagnosed severity, organ failure, clinical severity, and mortality were compared.

\section{Results}

A total of 224 patients with upper abdominal pain and referred to casualty were investigated. Among them, 164 patients had features of AP, according to the Atlanta classification. Of these 164 patients, 60 (36.58\%) were diagnosed as mild AP, 104 (63.41\%) were diagnosed as having SAP, 35 (33.65\%) developed organ failure before 72 hours, and 69 (66.3\%) underwent CT abdomen after 72 hours (based on the Atlanta classification severity). A total of 63 patients (60.57\%) needed intensive care admission, 15 (12.5\%) died during hospitalization, and four went against medical advice. The mean age of patients at presentation was 45.09 years (range 15-85).

\section{Etiology of pancreatitis}

Alcohol was found to be a significant cause of AP, and it was found in 115 (70.1\%) patients (Table 1). 


\section{Cureus}

\begin{tabular}{ll}
\hline Etiology & No of patients $(\mathrm{n}=164)$ \\
\hline Alcohol & $115(70.1 \%)$ \\
Gallstone disease & $33(20.12 \%)$ \\
Idiopathic & $15(9.1 \%)$ \\
Hypertriglyceridemia and gallstone disease & $20(12.2 \%)$ \\
Trauma & $1(0.06 \%)$
\end{tabular}

TABLE 1: Etiology of pancreatitis in study patients

\section{Modified CT severity index}

CT abdomen in 69 patients showed MCSI $\geqslant 8$ in all 69 (100\%) patients (Table 2 ).

\begin{tabular}{|l|r}
\hline Complications & No of patients \\
\hline Acute fluid collection & $56(81.15 \%)$ \\
Necrotizing pancreatitis & $49(71.01 \%)$ \\
Splenic vein thrombosis & $12(17.39 \%)$ \\
Pleural effusion/ascites/gastrointestinal involvement & $60(86.95 \%)$ \\
Portal vein thrombosis & $5(7.2 \%)$ \\
Distal superior mesenteric vein thrombosis & $1(1.44 \%)$ \\
MCSI $\geq 8$ & $69(100 \%)$
\end{tabular}

TABLE 2: Complications diagnosed with gold standard CT abdomen in study patients MCSI: modified CT severity index

\section{Comparison of scoring systems for prediction of severity in CT documented SAP patients}

Among the scoring systems, MGS had the highest sensitivity to predict severity as per CT findings. Ranson score at admission had the highest specificity and PPV. APACHE II and MGS had the highest diagnostic accuracy. Procalcitonin had the highest sensitivity, specificity, PPV, and diagnostic accuracy for CT documented severity (Table 3). 


\section{Cureus}

\begin{tabular}{|c|c|c|c|c|c|}
\hline Scoring system & $\begin{array}{l}\text { Sensitivity, \% }(95 \% \\
\text { Cl) }\end{array}$ & $\begin{array}{l}\text { Specificity, \% (95\% } \\
\text { Cl) }\end{array}$ & $\begin{array}{l}\text { PPV, \% (95\% } \\
\text { Cl) }\end{array}$ & $\begin{array}{l}\text { NPV, \% (95\% } \\
\text { Cl) }\end{array}$ & $\begin{array}{l}\text { Diagnostic accuracy, \% (95\% } \\
\mathrm{Cl})\end{array}$ \\
\hline APACHE II & $63.7(51.9-74.1)$ & $77.1(60.98-87.93)$ & 84.6 (72.4-91.9) & $\begin{array}{l}51.9(38.69- \\
64.9)\end{array}$ & $68.2(58.81-76.43)$ \\
\hline BISAP & $31.8(22.09-43.58)$ & $5.7(70.62-93.74)$ & $\begin{array}{l}81.4(63.3- \\
91.82)\end{array}$ & $\begin{array}{l}38.9(28.84- \\
50.13)\end{array}$ & 50 (40.56-59.44) \\
\hline MGS & $79.9(68.78-87.51)$ & $31.4(18.55-47.98)$ & $\begin{array}{l}69.6(58.77- \\
78.66)\end{array}$ & 44 (26.67-62.93) & $63.4(53.88-72.08)$ \\
\hline $\begin{array}{l}\text { Ranson at } \\
\text { admission }\end{array}$ & 44.9 (33.77-56.62) & $91.4(77.62-97.04)$ & $\begin{array}{l}91.1(77.04- \\
96.95)\end{array}$ & $\begin{array}{l}45.7(34.57- \\
57.3)\end{array}$ & 60.5 (50.97-69.43) \\
\hline $\begin{array}{l}\text { Ranson at } 48 \\
\text { hours }\end{array}$ & 63.7 (51.9-74.1) & $51.4(35.57-67.01)$ & $\begin{array}{l}72.1(59.83- \\
81.81)\end{array}$ & $\begin{array}{l}41.8(28.38- \\
56.67)\end{array}$ & 59.6 (50.01-68.54) \\
\hline rocalcitonin & 89.6 (82.79-93.38) & $100(92.59-100)$ & $100(96.44-100)$ & 80 (68.22-88.17) & $92.6(87.65-95.77)$ \\
\hline
\end{tabular}

TABLE 3: Comparing sensitivity, specificity, PPV, NPV, and diagnostic accuracy for four scores for 69 CT severity cases based on literature cut-off values

PPV: positive predictive value; NPV: negative predictive value; APACHE: acute physiology and chronic health evaluation; BISAP: bedside index for the severity in acute pancreatitis; MGS: modified Glasgow score; Cl: confidence interval

\section{Comparison of scoring systems in predicting SAP based on literature cut-off values}

Among the scoring systems, MGS had the highest sensitivity, NPV, and diagnostic accuracy, and all the four scores had better specificity and PPV as per the literature cut-off values for predicting severity in 164 AP patients. Procalcitonin had the highest sensitivity, NPV, and diagnostic accuracy as per the literature cut-off values for predicting severity in 164 AP patients (Table 4).

\begin{tabular}{|c|c|c|c|c|c|}
\hline Scoring system & $\begin{array}{l}\text { Sensitivity, \% (95\% } \\
\text { Cl) }\end{array}$ & $\begin{array}{l}\text { Specificity, \% (95\% } \\
\text { Cl) }\end{array}$ & $\begin{array}{l}\text { PPV, \% }(95 \% \\
\text { CI) }\end{array}$ & $\begin{array}{l}\text { NPV, } \%(95 \% \\
\text { Cl) }\end{array}$ & $\begin{array}{l}\text { Diagnostic accuracy, \% (95\% } \\
\text { Cl) }\end{array}$ \\
\hline APACHE II & $50(40.56-59.44)$ & $100(93.98-100)$ & $\begin{array}{l}100(93.12- \\
100)\end{array}$ & $\begin{array}{l}53.57(44.37- \\
62.54)\end{array}$ & $68.29(60.82-74.93)$ \\
\hline BISAP & $25.96(18.5-35.14)$ & $100(93.98-100)$ & $\begin{array}{l}100(87.54- \\
100)\end{array}$ & $\begin{array}{l}43.8(35.77- \\
52.16)\end{array}$ & $53.05(45.43-60.53)$ \\
\hline MGS & $75.96(66.92-83.15)$ & $100(95.36-100)$ & $\begin{array}{l}100(95.36- \\
100)\end{array}$ & $\begin{array}{l}70.59(60.18- \\
79.21)\end{array}$ & $84.76(78.46-89.46)$ \\
\hline $\begin{array}{l}\text { Ranson at } \\
\text { admission }\end{array}$ & 32.69 (24.43-42.18) & $100(93.98-100)$ & $\begin{array}{l}100(89.85- \\
100)\end{array}$ & $\begin{array}{l}46.15(37.82- \\
54.71)\end{array}$ & $57.32(49.66-64.63)$ \\
\hline $\begin{array}{l}\text { Ranson at } 48 \\
\text { hours }\end{array}$ & $58.65(49.05-67.65)$ & 100 (93.98-100) & $\begin{array}{l}100(94.08- \\
100)\end{array}$ & $\begin{array}{l}58.25(48.6- \\
67.31)\end{array}$ & 73.78 (66.56-79.91) \\
\hline Procalcitonin & 89.66 (82.79-93.38) & $100(92.59-100)$ & $\begin{array}{l}100(96.44- \\
100)\end{array}$ & $80(68.22-88.17)$ & 92.68 (87.65-95.77) \\
\hline
\end{tabular}

TABLE 4: Diagnostic values of four scoring systems and procalcitonin when all acute pancreatitis patients compared

PPV: positive predictive value; NPV: negative predictive value; APACHE: acute physiology and chronic health evaluation; BISAP: bedside index for the severity in acute pancreatitis; MGS: modified Glasgow score; Cl: confidence interval 


\section{Cureus}

ROC curves plotted using the data for four scores and procalcitonin

On the basis of the highest sensitivity and specificity values generated from the ROC curves, the following cut-offs were selected for further analysis: Ranson $\geqslant 2$, Glasgow $\geqslant 3$, BISAP $\geqslant 2$, APACHE II $\geqslant 6$, and procalcitonin $\geqslant 1.5 \mathrm{ng} / \mathrm{mL}$. Ranson score on admission had the highest area under the curve (AUC) based on the ROC curve to predict SAP among the four scoring systems (Figure 1).

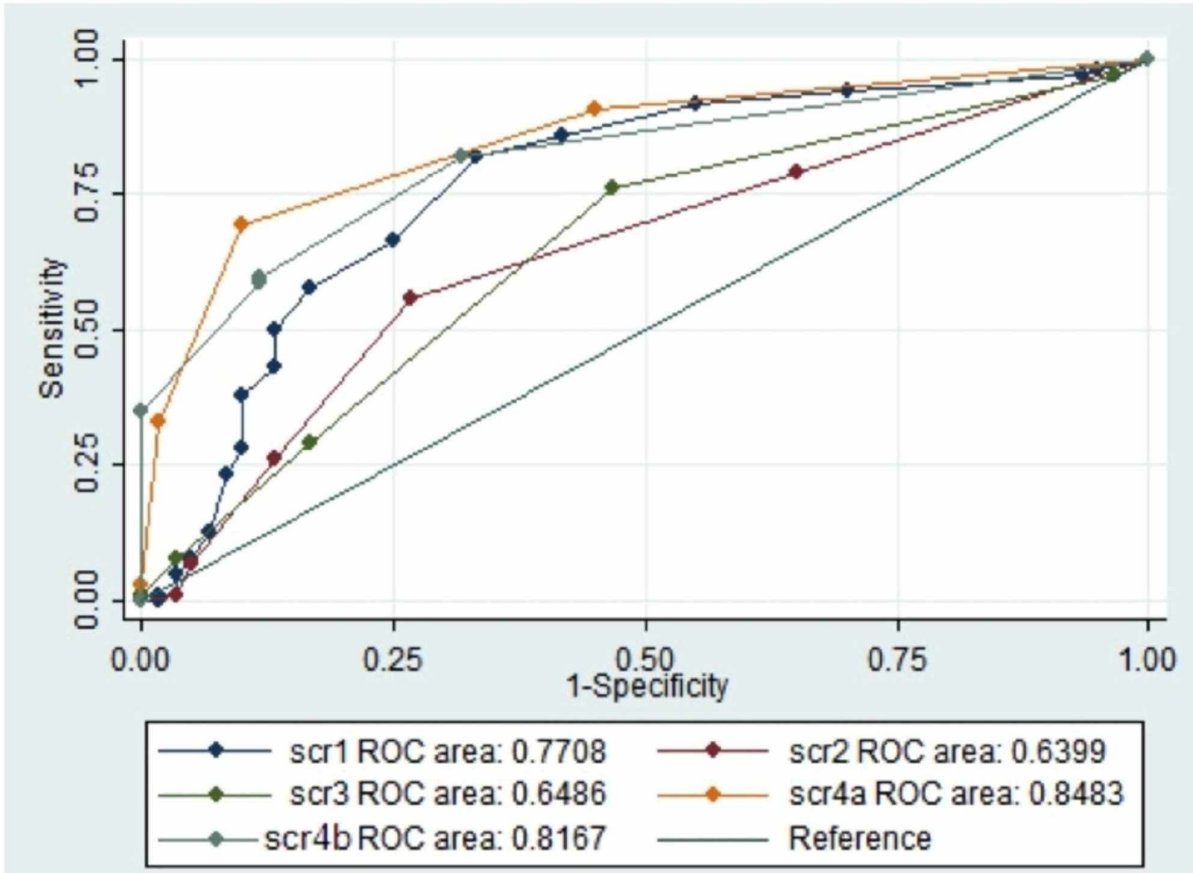

FIGURE 1: ROC curves four scores and procalcitonin in study patients

ROC: receiver operator characteristic; score 1: acute physiology and chronic health evaluation II; score 2: bedside index for the severity in acute pancreatitis; score 3: modified Glasgow score; score 4a: Ranson score at admission; score $4 \mathrm{~b}$ : Ranson score 48 hours after admission.

\section{Comparison of scoring systems in SAP patients with cut-off points generated by ROC curves}

When a cut-off for APACHE II $\geqslant 8$ was used as per the literature, it could predict severity in 69 (66.3\%) patients, whereas when the cut-off was improved to $\geqslant 6$ based on the ROC curve from this study, we could predict severity in 85 (81.7\%) AP patients (Table 5). 


\section{Cureus}

\begin{tabular}{|c|c|c|}
\hline Scoring system & With literature cut-off & With ROC curve generated study cut-off \\
\hline APACHE & $66.34 \%(n=69)$ & $81.7 \%(n=85)$ \\
\hline BISAP & $21.15 \%(n=22)$ & $55.76 \%(n=58)$ \\
\hline MGS & $52.58 \%(n=55)$ & $52.58 \%(n=55)$ \\
\hline Ranson at admission & $29.80 \%(n=31)$ & $75.96 \%(n=79)$ \\
\hline Ranson at 48 hours & $34.61 \%(n=44)$ & $42.30 \%(n=62)$ \\
\hline Procalcitonin & $100 \%(n=104)$ & $100 \%(n=104)$ \\
\hline
\end{tabular}

\section{TABLE 5: Comparison of scoring systems in SAP patients with cut-off points generated by ROC}

curves

APACHE: acute physiology and chronic health evaluation; BISAP: bedside index for the severity in acute pancreatitis; MGS: modified Glasgow score; ROC: receiver operator characteristic

\section{Comparison of scoring systems for association with organ failure}

APACHE II and MGS had the highest sensitivity and diagnostic accuracy in predicting organ dysfunction. Ranson score had the highest specificity. Procalcitonin had the highest specificity, sensitivity, PPV, NPV, and diagnostic accuracy for association with organ failure (Table 6).

\begin{tabular}{|c|c|c|c|c|c|}
\hline Scoring system & $\begin{array}{l}\text { Sensitivity, } \\
\%\end{array}$ & $\begin{array}{l}\text { Specificity, } \\
\%\end{array}$ & $\begin{array}{l}\text { PPV, } \\
\%\end{array}$ & $\begin{array}{l}\text { NPV, } \\
\%\end{array}$ & $\begin{array}{l}\text { Diagnostic accuracy, } \\
\%\end{array}$ \\
\hline APACHE II & 48.5 & 36.2 & 27.8 & 58.1 & 40.3 \\
\hline BISAP & 8.5 & 55 & 8.8 & 54.2 & 39.4 \\
\hline MGS & 68.5 & 20.2 & 30.3 & 56 & 36.5 \\
\hline $\begin{array}{l}\text { Ranson at } \\
\text { admission }\end{array}$ & 14.2 & 68.1 & 18.5 & 61 & 50 \\
\hline $\begin{array}{l}\text { Ranson at } 48 \\
\text { hours }\end{array}$ & 22.8 & 36.2 & 15.3 & 48 & 31.7 \\
\hline Procalcitonin & 100 & 100 & 100 & 100 & 100 \\
\hline
\end{tabular}

\section{TABLE 6: Comparison of scoring systems for association with organ failure in study patients}

APACHE: acute physiology and chronic health evaluation; BISAP: bedside index for the severity in acute pancreatitis; MGS: modified Glasgow score

\section{Mortality among AP patients predicted by various scores}

APACHE II score was associated with mortality in SAP in 12 (63.15\%) patients when a cut-off $\geqslant 8$ was used as per the literature, but when the cut-off was improved to $\geqslant 10$ based on the ROC curve from this study, the association was in eight (42.1\%) patients (Table 7). 


\section{Cureus}

\begin{tabular}{|c|c|c|}
\hline Scoring system & With literature cut-off & With ROC curve generated study cut-off \\
\hline APACHE & $63.15 \%(n=12)$ & $42.1 \%(n=8)$ \\
\hline BISAP & $42.1 \%(n=8)$ & $68.4 \%(n=13)$ \\
\hline MGS & $63.1 \%(n=12)$ & $63.1 \%(n=12)$ \\
\hline Ranson at admission & $26.3 \%(n=5)$ & $52.6 \%(\mathrm{n}=10)$ \\
\hline Ranson at 48 hours & $52.63 \%(n=10)$ & $57.89 \%(n=11)$ \\
\hline Procalcitonin & $15 \%(n=3)$ & $47 \%(n=9)$ \\
\hline
\end{tabular}

\section{TABLE 7: Mortality among acute pancreatitis patients predicted by various scores}

APACHE: acute physiology and chronic health evaluation; BISAP: bedside index for the severity in acute pancreatitis; MGS: modified Glasgow score; ROC: receiver operator characteristic

During follow-up, scores and procalcitonin during the first admission in AP did not have much bearing in the prediction of chronicity.

\section{Discussion}

AP is an inflammatory condition of the pancreas and may have a variable severity. Most of the patients have mild disease with minimal morbidity, and the rest of the patients have $10 \%-20 \%$ of mortality in SAP [6]. In this study based on MCSI, there were 69 (42\%) SAP patients who are similar to Bezmarevic et al. study [7]. Cho et al. in their study of 161 AP patients reported that 52 patients with SAP had APACHE II score $\geqslant 8$ similar to this study [8]. Khanna et al. reported higher sensitivity, specificity, and diagnostic accuracy for APACHE II score $\geqslant 8$ for predicting severity [9]. Similar to this study, they reported that the APACHE II score had the best AUC for association with mortality [9].

Similar to this study, Cho et al. in their study reported that BISAP score $\geqslant 3$ predicted SAP and increased mortality [8]. In their study, they reported that patients with BISAP score $\geqslant 3$ had 76.1 more times a chance to develop SAP and 121.7 times associated with mortality [9]. Five SAP patients with organ failure had BISAP score $\geqslant 3$, similar to this study [10]. Khanna et al. reported that BISAP scores $\geqslant 3$ had higher sensitivity (74\%) but less specificity (68\%) than this study [9]. Park et al. concluded that the BISAP score of 2 was significant statistically for predicting SAP, organ failure, and mortality [11]. AUC for BISAP for predicting severity in AP was 0.8 , and for mortality, it was 0.86 [11]. AUC for Ranson score predicting the severity of AP was 0.74 and for mortality 0.74 [11]. In contrast to this study, the BISAP score had better accuracy for SAP.

Similar to this study, Khanna et al. reported that the MGS had diagnostic accuracy was $75 \%$ for predicting SAP [9]. Khanna et al. also reported that the Ranson score had better AUC for predicting severity [9]. Papachristou et al. reported that Ranson score had better AUC for predicting severity (0.94) and mortality (0.95), in comparison to this study [12]. Cho et al. in their study found that AUC for Ranson score for predicting severity in AP was 0.804 (0.717-0.892) with a sensitivity of $81.8 \%$, specificity of $59.1 \%$, and PPV of $76.9 \%$ and for association with mortality 0.861 (0.734-0.988) with sensitivity of $87.5 \%$, specificity of $57.2 \%$, and PPV of 5.3\% [8]. Three SAP patients with organ failure had Ranson score $\geqslant 3$ on admission and 17 patients had Ranson score $\geqslant 3$ after 48 hours of admission, in comparison to our study [10]. Simoes et al. reported that the Ranson score had a higher sensitivity of $91.2 \%$ in predicting severity, but had lesser specificity compared to this study [13]. Kim et al. reported that the Ranson score had the highest accuracy based on AUC [14]. Woo et al. reported that $3.29 \mathrm{ng} / \mathrm{mL}$ had better accuracy for predicting severity [15]. Khanna et al. reported that procalcitonin had an AUC of 0.88 for predicting severity [9]. 
specificity were done using the Wilson method using OpenEpi online calculator.

\section{Conclusions}

MGS had the highest sensitivity for predicting the severity of AP. However, Ranson score at admission had better diagnostic accuracy for predicting severity, organ failure, and mortality based on ROC curves. Procalcitonin had the best sensitivity, specificity, PPV, NPV, and diagnostic accuracy for association with severity in AP. BISAP score may be calculated within 24 hours of admission, but APACHE II and MGS had better diagnostic accuracy. Ranson score at admission is the best one for prediction of severity in AP among the four scores. APACHE II score is the best one for association with mortality in SAP patients. Procalcitonin on admission had the best sensitivity, specificity, PPV, and diagnostic accuracy for predicting severity in AP, organ failure, and mortality.

\section{Additional Information}

\section{Disclosures}

Human subjects: Consent was obtained by all participants in this study. Institute Ethics Committee (Human studies) Reg.No ECR/342/Inst/PY/2013 issued approval JIP/IEC/SC/2014/8/654. Animal subjects: All authors have confirmed that this study did not involve animal subjects or tissue. Conflicts of interest: In compliance with the ICMJE uniform disclosure form, all authors declare the following: Payment/services info: All authors have declared that no financial support was received from any organization for the submitted work. Financial relationships: All authors have declared that they have no financial relationships at present or within the previous three years with any organizations that might have an interest in the submitted work. Other relationships: All authors have declared that there are no other relationships or activities that could appear to have influenced the submitted work.

\section{References}

1. Theoni RF: The revised Atlanta classification of acute pancreatitis: its importance for the radiologist and its effect on treatment. Radiology. 2012, 262:751-764. 10.1148/radiol.11110947

2. Tandon RK: Management of acute pancreatitis: Indian guidelines and protocols . API Med Update. 2013, 23:267-270.

3. Kumar M, Chinnakkulam Kandhasamy S, Sahoo AK, Amaranathan A, Goneppanavar M, Nelamangala Ramakrishnaiah VP: Pigtail catheter drainage and surgery in severe acute pancreatitis . JGH Open. 2019, 3:429-434. 10.1002/jgh3.12182

4. Yadav D: Reassessing the risk of pancreatitis with alcohol . Pancreas. 2016, 45:781-782. 10.1097/MPA.0000000000000668

5. Rebours V, Vullierme MP, Hentic O, et al.: Smoking and the course of recurrent acute and chronic alcoholic pancreatitis: a dose-dependent relationship. Pancreas. 2012, 41:1219-1224. 10.1097/MPA.0b013e31825de97d

6. Banks PA: Acute pancreatitis: landmark studies, management decisions, and the future . Pancreas. 2016, 45:633-640. 10.1097/MPA.0000000000000632

7. Bezmarevic M, Kostic Z, Jovanovic M, et al.: Procalcitonin and BISAP score versus C-reactive protein and APACHE II score in early assessment of severity and outcome of acute pancreatitis. Vojnosanit Pregl. 2012, 69:425-431. 10.2298/VSP1205425B

8. Cho JH, Kim TN, Chung HH, Kim KH: Comparison of scoring systems in predicting the severity of acute pancreatitis. World J Gastroenterol. 2015, 21:2387-2394. 10.3748/wjg.v21.i8.2387

9. Khanna AK, Meher S, Prakash S, et al.: Comparison of Ranson, Glasgow, MOSS, SIRS, BISAP, APACHE-II, CTSI Scores, IL-6, CRP, and procalcitonin in predicting severity, organ failure, pancreatic necrosis, and mortality in acute pancreatitis. HPB Surg. 2013, 2013:367581. 10.1155/2013/367581

10. Mounzer R, Langmead CJ, Wu BU, et al.: Comparison of existing clinical scoring systems to predict persistent organ failure in patients with acute pancreatitisis. Gastroenterology. 2012, 142:1476-1482. 10.1053/j.gastro.2012.03.005

11. Park JY, Jeon TJ, Ha TH, et al.: Bedside index for severity in acute pancreatitis: comparison with other scoring systems in predicting severity and organ failure. Hepatobiliary Pancreat Dis Int. 2013, 12:645-650. 10.1016/s1499-3872(13)60101-0

12. Papachristou GI, Muddana V, Yadav D, et al.: Comparison of BISAP, Ranson's, APACHE-II, and CTSI scores in predicting organ failure, complications, and mortality in acute pancreatitis. Am J Gastroenterol. 2010, 105:435-441. 10.1038/ajg.2009.622

13. Simoes M, Alves P, Esperto H, et al.: Predicting acute pancreatitis severity: comparison of prognostic scores . Gastroenterol Res. 2011, 4:216-222. doi: 10.4021/gr364w

14. Kim YS, Lee BS, Kim SH, Seong JK, Jeong HY, Lee HY: Is there correlation between pancreatic enzyme and radiological severity in acute pancreatitis?. World J Gastroenterol. 2008, 14:2401-2405. 10.3748/wjg.14.2401

15. Woo SM, Noh MH, Kim BG, et al.: Comparison of serum procalcitonin with Ranson, APACHE-II, Glasgow and Balthazar CT severity index scores in predicting severity of acute pancreatitis. Korean J Gastroenterol. 2011, 58:31-37. 10.4166/kjg.2011.58.1.31 